\title{
BLAISE CRONIN E A CIÊNCIA DA INFORMAÇÃO NA PERSPECTIVA SOCIAL
}

\author{
BLAISE CRONIN AND INFORMATION SCIENCE IN \\ SOCIAL PERSPECTIVE
}

\author{
Jobson Louis Santos de Almeidaa \\ Gustavo Henrique de Araújo Freire ${ }^{b}$ \\ Henry Poncio Cruz de Oliveirac
}

\begin{abstract}
RESUMO
Introdução: Discute o lado social da Ciência da Informação, perpassando por uma reflexão sobre a influência social que há neste campo, a compreensão da percepção de Blaise Cronin sobre a informação enquanto recurso estratégico organizacional, e a identificação das temáticas tratadas por este pesquisador ao longo de sua carreira, o que nos permite conhecer a influência deste nos pressupostos teóricos do campo científico. Objetivo: O objetivo do artigo é apresentar para a comunidade científica brasileira uma reflexão acerca da trajetória histórico-evolutiva do pensamento e das contribuições teóricas do cientista Blaise Cronin na e para a Ciência da Informação. Metodologia: Foram utilizadas as técnicas de pesquisa bibliográfica e de análise de conteúdo para o estudo dos artigos de autoria de Blaise Cronin recuperados pelo Portal de Periódicos da CAPES. Resultados: O estudo apresenta que Blaise Cronin ao longo de 34 anos de carreira, realizou investigações com ênfase em marketing e gestão, indústria da informação, bibliometria e comunicação científica. Evidencia o potencial de contribuição deste cientista para os estudos contemporâneos sobre Política e Economia da Informação, apontando possibilidades de novas pesquisas, a partir do seu legado científico. Conclusões: Após um período de doze meses estudando oitenta e um artigos científicos de Blaise Cronin, concluímos o estudo cientes da contribuição responsável que ele traz para o campo científico no Brasil ao evidenciar que o pensamento do Professor Cronin é contemporâneo, relevante e necessário tanto para o campo científico, quanto para a atuação profissional dos bibliotecários.
\end{abstract}

Descritores: Ciência da Informação. Ciência Social. Epistemologia da Ciência da

a Doutor em Ciência da Informação pelo Programa de Pós-Graduação em Ciência da Informação da Universidade Federal da Paraíba (UFPB).E-mail: jobsonlouis@gmail.com

b Doutor em Ciência da Informação pela Universidade Federal do Rio de Janeiro (UFRJ) e Instituto Brasileiro de Informação em Ciência e Tecnologia (IBICT). Professor do Programa de Pós-Graduação em Ciência da Informação da Universidade Federal da Paraiba (UFPB). Email: ghafreire@gmail.com

c Doutor em Ciência da Informação pelo Programa de Pós-Graduação em Ciência da Informação da Universidade Estadual Paulista Julho de Mesquita Filho (UNESP). Professor do Departamento de Ciência da Informação (DCl) e do Programa de Pós-Graduação em Ciência da Informação da Universidade Federal da Paraíba (UFPB). E-mail: henry.poncio@gmail.com

Inf. Inf., Londrina, v. 24, n. 3, p. 230 - 259, set./dez. 2019.

http://www.uel.br/revistas/informacao/ 
Informação. Economia da informação. Blaise Cronin.

\section{INTRODUÇÃO}

No século $X X$ o mundo vivenciou inúmeras e profundas mudanças $e$ dentre elas podemos destacar o advento da Ciência da Informação $(\mathrm{Cl})$ após a Segunda Guerra Mundial, com estudos voltados para as problemáticas em torno da informação, sua gênese e seus processos, fluxos, efeitos e consequências para a ciência e para a sociedade.

Conhecemos as contribuições teóricas de precursores que viveram em séculos anteriores a este, tais como Gabriel Naudé (séculos XVII, XVIII e XIX), Melvil Dewey e Paul Otlet (séculos XIX e XX), além de muitos outros clássicos e contemporâneos que formam o arcabouço teórico desta ciência, a exemplo de Rafael Capurro, Birger Hjorland, Harold Borko, Yves Le Coadic, Armand Mattelart, Gernot Wersig e tantos outros cientistas que são citados e estudados no Brasil. Entretanto, verifica-se que a ciência brasileira não está imune à invisibilidade ou ao pouco conhecimento das contribuições de alguns cientistas da informação, já consagrados em nível mundial, mas que ainda não são conhecidos ou devidamente reconhecidos pela comunidade científica nacional.

Partindo da supracitada premissa, a pesquisa que deu origem ao presente trabalho teve o propósito de investigar e estudar a produção científica de Blaise Cronin. Conhecido popularmente como Professor Cronin, este cientista da informação e bibliométrico de dupla cidadania (irlandês e americano), é Professor Emérito de Ciência da Informação na Universidade de Indiana, nos Estados Unidos. Atuou como Editor-Chefe dos periódicos científicos Jornal da Associação de Ciência da Informação e Tecnologia (Journal of the Association for Information Science and Technology - JASIST) durante sete anos, e da Revisão Anual da Ciência da Informação e Tecnologia (Annual Review of Information Science and Technology - ARIST) durante uma década. Ele também publicou mais de 300 obras, dentre as quais se destacam: artigo, monografias, relatórios técnicos, documentos de conferências, e outras publicações. O ARIST, por exemplo, foi de 1966 a 2011 uma publicação de referência na comunidade 
da Ciência da Informação, possibilitando que anualmente os pesquisadores tivessem um panorama do cenário da ciência e tecnologia da informação, fornecendo uma visão analítica e acessível sobre tendências e desenvolvimentos significativos neste campo científico.

Os títulos de seus livros servem de indícios para que possamos identificar três das principais temáticas frequentemente abordadas e estudadas por este pesquisador, a saber: informação científica/bibliometria, políticas de informação e gestão da informação. Blaise Cronin é mundialmente conhecido não somente como palestrante e orador em conferências nacionais e internacionais, mas também pela sua ampla atuação como pesquisador e consultor em mais de 30 países.

Feita esta breve contextualização acerca da carreira do cientista escolhido para esse estudo, esclarecemos que esta pesquisa é fruto dos estudos realizados a partir da disciplina Fundamentos Teóricos da Ciência da Informação, no âmbito do Programa de Pós-Graduação em Ciência da Informação, em nível de Doutorado, na Universidade Federal da Paraíba, e que subsidia a fundamentação teórica de uma pesquisa de Tese em andamento sobre políticas de informação.

O objetivo deste trabalho é apresentar uma reflexão acerca da trajetória histórico-evolutiva do pensamento e das contribuições teóricas do cientista Blaise Cronin na e para a Ciência da Informação. Neste contexto, discutem-se também o lado social desta ciência e o conceito de informação, perpassando por uma reflexão sobre a influência sociológica que há nos estudos realizados neste contexto científico, a compreensão da percepção deste pesquisador sobre a informação enquanto recurso estratégico para as organizações, e a identificação das temáticas e demais questões relevantes tratadas por este cientista que nos permitem conhecer a influência deste nos pressupostos teóricos da $\mathrm{Cl}$ e sua evolução teórico-conceitual.

\section{METODOLOGIA}

A pesquisa caracteriza-se como de natureza quanti-qualitativa, do tipo 
descritiva e exploratória, que fez uso das técnicas de pesquisa bibliográfica para coleta de dados e de análise de conteúdo para garantir a exequibilidade de suas análises. Foram analisados artigos de autoria de Blaise Cronin, recuperados pelo Portal de Periódicos da CAPES, uma importante fonte de informação que reúne as principais bases de dados nacionais e internacionais utilizadas por pesquisadores e cientistas brasileiros.

Quanto aos procedimentos e critérios adotados para busca no referido Portal, esta foi realizada por meio de acesso institucional às bases de dados, via instituições públicas federais de ensino no Brasil, que oportunizaram acesso mais amplo às bases de dados científicos. Foram adotados três critérios para o refinamento da busca e para a seleção dos artigos, a saber: autoria, tipo de recurso e texto revisado por pares. A autoria foi definida no campo de busca, utilizando os seguintes termos: "Cronin, Blaise", "Blaise Cronin" e "B. Cronin", conforme sugestão de refinamento da própria ferramenta de busca do Portal.

Quanto ao tipo de recurso, foi possível recuperar em sua maioria e em ordem decrescente, respectivamente, artigos, resenhas, resumos expandidos de comunicação e editoriais. Em maior número de publicações e o tipo de recurso analisado nesta investigação foi "Artigos" com autoria atribuída a Blaise Cronin, sendo excluídas da análise neste presente trabalho os editoriais, as resenhas e os resumos expandidos de comunicação recuperados nesta ferramenta. Tais publicações deverão ser objeto de análise e estudo em pesquisas futuras. A partir dos critérios supracitados, optou-se por analisar apenas os artigos de periódicos revisados por pares e disponíveis em texto completo, sendo recuperados e analisados na íntegra, portanto, 81 (oitenta e uma) publicações desta natureza, considerando autoria individual e coautoria.

Posterior a etapa de pesquisa bibliográfica, procedeu-se com a análise de conteúdo. Esta, de acordo com Vergara (2010, p. 7), vem sendo amplamente utilizada e desenvolvida desde o começo do século XX como uma técnica aplicada, principalmente, no tratamento de material jornalístico. Contudo, neste início de século XXI observa-se também aplicação desta técnica para a análise de documentos institucionais, transcrições de entrevistas, entre outras situações em que se faz necessário o emprego de uma técnica para tratar dados e 
identificar o conteúdo de mensagens, textos e comunicações em geral, tanto em abordagens quantitativas, quanto qualitativas, ou mesmo quanti-qualitativas, como é o caso da abordagem da presente pesquisa (ELO; KYNGAS, 2008). Utilizou-se a análise de conteúdo indutiva, em que as categorias são criadas a partir dos dados a serem analisados, de acordo com Richardson (2017), em que o primeiro passo consiste em organizar os dados qualitativos, por meio de codificação aberta, criação de categorias e abstração, na tentativa de descrever todos os aspectos do conteúdo.

Neste trabalho, a aplicação da análise de conteúdo contribuiu para identificar e compreender as abordagens temáticas e de cunho teóricoconceitual presentes nas publicações de Blaise Cronin recuperadas no Portal de Periódicos da CAPES em texto completo. Este procedimento oportunizou a construção de uma reflexão acerca da trajetória histórico-evolutiva do pensamento e das contribuições teóricas deste cientista na e para a Ciência da Informação.

Na primeira fase, denominada pré-análise, foram realizadas a tradução e a leitura dos resumos do material recuperado no Portal de Periódicos da CAPES, com base em três critérios de refinamento permitidos nesta ferramenta, a saber: autoria, tipo de recurso e texto revisado por pares. Com base em Bardin (1977), foram obedecidos os princípios de exaustividade, representatividade, homogeneidade e pertinência, que são facilmente percebidos, respectivamente, ao observarmos que nesta pesquisa foi decidido analisar todos os artigos completos e revisados por pares recuperados nas bases de dados, cuja autoria é de Blaise Cronin e encontram-se inseridos no contexto do campo científico da Ciência da Informação.

A segunda fase consistiu na exploração do material, considerando a análise de todos os artigos na íntegra, sem prejuízo na tradução. A partir desta fase foi possível criar categorias e subcategorias para descrição das publicações considerando as temáticas e sua cronologia, possibilitando um maior aprofundamento da análise.

A terceira fase, de inferências, consistiu em interpretação do conteúdo e na discussão dos resultados, cuja apresentação dar-se-á nas três seções 
seguintes, que versam sobre a produção científica de Blaise Cronin na e para a Ciência da Informação, a perspectiva social desta ciência e por fim, as contribuições e possibilidades de estudos e pesquisas na Ciência da Informação brasileira a partir das informações obtidas na análise.

\section{A PRODUÇÃO CIENTÍFICA DO PROFESSOR CRONIN NA CIÊNCIA DA INFORMAÇÃO}

Verificou-se maior formalidade dos artigos deste autor a partir da década de 90, com estrutura aproximada aos artigos da atualidade, com introdução, metodologia, resultados, discussão e conclusão, algo que acompanha a própria evolução das publicações científicas. Nos anos 80 os artigos possuíam estrutura variável e muitos posicionamentos pessoais do autor com relação a assuntos pertinentes ao campo científico da Biblioteconomia e da Ciência da Informação, com destaque para análise e reflexões acerca da realidade de alguns países e das investigações e publicações do seu próprio campo de atuação. Observouse, também, que nas décadas de 80 e 90 a ampla maioria dos seus artigos foi de autoria individual, e nos anos 2000, a ampla maioria dos artigos foram em coautoria com outros cientistas/pesquisadores/profissionais.

Para uma melhor compreensão e discussão acerca da temática dos artigos de Blaise Cronin, estes foram divididos em quatro períodos de tempos, oportunizando uma compreensão e reflexão mais detalhada acerca da trajetória histórico-evolutiva do pensamento e das contribuições teóricas desse cientista.

\subsection{Período de 1980-1984: ÊNFASE Em MARKeting E GeStÃo dA INFORMação}

Na primeira década dos anos 80 , dez temáticas se destacam, a saber: Marketing em biblioteca; Bibliometria; Comunicação científica; Recuperação da informação on-line; Necessidades dos usuários da informação; Gestão da informação; Efeitos da crise econômica na biblioteca pública; Novas Tecnologias de Comunicação; Mudanças e evolução do Profissional da Informação; Educação a Distância e Aprendizagem Aberta em Biblioteconomia. No entanto, quanto a temática mais frequente em suas publicações, destacam-se o 
Marketing em bibliotecas e a Gestão da Informação.

A respeito do marketing em bibliotecas, podemos citar algumas lições aprendidas. Na primeira delas, Cronin (1981, p. 383) menciona Patricia Berger (Bibliotecária norte-americana e ex-presidente da American Library AssociationALA) ao afirmar que a estabilidade financeira das bibliotecas públicas depende de um programa de relações públicas ao invés de incidentes isolados; de métodos preventivos de longo alcance, ao invés de uma abordagem corretiva ou orientada para a crise. Tudo isso contribuiria com o convencimento das comunidades sobre a indispensabilidade da biblioteca e dos serviços de informação por ela prestados.

Uma segunda lição sobre marketing da informação, conforme Cronin (1982a, p. 391), é que "Marketing tem a ver com comunicação e troca". Para Cronin (1982a), a tarefa do bibliotecário é falar amplamente sobre o serviço de biblioteca, abrindo tantos canais de comunicação quanto forem possíveis dentro da organização ou instituição. A respeito da troca, ele menciona que os serviços relevantes prestados para seus usuários na biblioteca devem receber apoio e divulgação por parte destes. É nesta troca de serviço por apoio/divulgação que consiste a essência de uma abordagem de marketing para o gerenciamento de bibliotecas. Nesse sentido, os dois objetivos de apoio da biblioteca para ele são satisfazer as necessidades de usuários da forma mais eficaz possível e criar um ambiente saudável para a população de usuários nos serviços oferecidos pela biblioteca.

Cronin (1982a) destaca que bibliotecários precisam preocupar-se menos com medidas quantitativas de desempenho (a exemplo de estatísticas de empréstimos) e mais com os benefícios e a satisfação dos usuários, que são aspectos qualitativos do marketing. Na prática, isso significa maior flexibilidade de atitude e vontade de procurar maneiras pelas quais o serviço de biblioteca poderia contribuir com os grupos de usuários que estão servindo. Assim, o Marketing não é um dogma, mas sim uma atitude mental. Ele faz uma analogia ao transporte pago de pessoas, ao dizer que o marketing coloca o bibliotecário no comando, mas que sempre é importante lembrar que o usuário é o passageiro pagador e, nesse sentido, os desejos dele vem antes dos caprichos e 
preferências do motorista (bibliotecário).

A abordagem de marketing para gestão de uma biblioteca envolve necessariamente uma compreensão dos objetivos organizacionais e uma disposição para identificar as necessidades do usuário, para implementar políticas destinadas a aumentar a satisfação deste e avaliar o desempenho. Paradoxalmente, Cronin (1982b) diz que a força do serviço da biblioteca é a causa de sua fraqueza. Afinal, a biblioteca é forçada a dispersar seus recursos cada vez menores em uma gama cada vez maior de funções e atividades especializadas. E, neste caso, a biblioteca torna-se incapaz de manter o nível de serviço adequado e esperado. Para ele isso cria problemas para formulação de políticas. O gerente da biblioteca tem que tomar decisões difíceis perante tal realidade. Neste contexto, Cronin (1982b, p. 277) faz a defesa da "Gestão por Objetivos". Ele diz que se um serviço tem uma visão firme da direção em que vai, se tiver uma tabela de prioridades e tarefas futuras, então as decisões dolorosas podem mais facilmente serem tomadas.

No contexto inicial dos anos 80 isso é ainda mais relevante para o serviço de biblioteca contemporânea, já que, tenta ser tudo para todos os públicos. Aponta como sendo necessárias uma maior racionalização nos modos de prestação de serviços e uma maior seletividade na comercialização de serviços bibliotecários.

A respeito das novas tecnologias que afetam a vida dos bibliotecários e das bibliotecas, Cronin ressalta que o bibliotecário terá um futuro assegurado, se frente às novas demandas, assumir o papel de ensinar como usar os ambientes eletrônicos/digitais de informação, prestar consultoria de estratégias de busca, auxiliar na avaliação de informações de qualidade, entre outros novos papéis. Isso remonta às discussões contemporâneas sobre desenvolvimento de competências em informação, fake news, buscadores e metabuscadores neste século XXI.

Cronin (1984) discorre que o advento da chamada era da informação para os bibliotecários significa enfrentar um conjunto sem precedentes de desafios complexos de inserção para atuação destes na sociedade da informação emergente. Afirma que a tendência para a informação desinstitucionalizada, seu 
manuseio e processamento, geram todo tipo de perguntas para o serviço tradicional de biblioteca. É notório que os bibliotecários estão se perguntando até os dias atuais sobre a importância e permanência do seu papel na crescente economia da informação. As crises econômicas dos países europeus é um tema recorrente nas publicações de Blaise Cronin nos anos 80 sobre Marketing, questionando-se, por exemplo, se a privatização é uma possibilidade para as bibliotecas. $\mathrm{O}$ autor menciona que depois de mais de um século, o movimento das bibliotecas públicas no Reino Unido, por exemplo, ainda não tem um senso coerente de propósito, ou uma forte imagem pública. É, em vez disso, uma agregação de serviços locais, iniciativas e filosofias de gestão. Cronin (1984) aposta que a adoção de uma abordagem de marketing não fornecerá respostas a esta questão, mas pode ajudar a esclarecer alguns dos problemas. Afirma que os princípios e práticas de marketing aplicados ao gerenciamento de serviços de biblioteca pública pode ser um passo na direção certa.

Quanto a gestão da informação, é interessante observar que Cronin (1984) aborda o aumento da importância dos recursos informacionais para os governos de diversas nações, destacando que a política do governo deve ser projetada para promover o desenvolvimento e uso de recursos de informação, eliminando as barreiras e os impedimentos para o desenvolvimento e uso destes. Afirma, ainda, que a interação público/privado é uma questão política complexa e mundialmente relevante, devido, em grande parte, à evolução das tecnologias da informação e comunicação.

Cronin (1984) cita que Zurkowski (1981) refutou a divisão dicotômica público/privado, alegando ser esta inadequada, pois há três "jogadores" (atores) neste contexto, a saber: 1) as instituições e agências governamentais; 2) os órgãos sem fins lucrativos, quase governamentais (ou quase privados); e 3) as empresas do setor privado. Cronin (1984, p. 374-375, tradução nossa) ainda citando e destacando Zurkowski (1981) diz que:

Uma estrutura de informação pluralista saudável (...) é como um banco de três pernas, em que cada perna é indispensável para o funcionamento eficaz do todo. O governo é responsável por estabelecer o quadro geral como coletor de dados e de estatísticas, um financiador de programas de pesquisa, como órgão regulador, e como um estimulador de iniciativas 
relacionadas à informação no setor privado. O setor privado, que inclui editoras, livrarias, produtores de bancos de dados e corretores de informações, é responsável pela criação de serviços, pela agregação de valor aos serviços e investir capital de risco para desenvolver novas oportunidades de mercado que de outra forma não poderia ser aberto. A terceira perna do tripé inclui associações de pesquisa, órgãos profissionais e bibliotecas públicas, sendo que a última possui responsabilidade social por fornecer e manter acesso livre às fontes de informação para a população como um todo. Uma economia da informação saudável depende da interação bem-sucedida e equilibrada entre esses três elementos.

Cronin (1984) afirma que os autores são os únicos atores sociais desse contexto que parecem não ter voz e questiona de forma reflexiva em que medida esses autores devem ser consultados durante o desenvolvimento futuro de sistemas de publicação eletrônica nos anos vindouros. Na contemporaneidade, emerge o debate sobre a Ciência Aberta e os Dados Abertos, uma discussão que não pode excluir os autores das pesquisas científicas.

Por fim podemos destacar que os estudos bibliométricos são uma constante ao longo da carreira de Blaise Cronin, e se mesclam, neste período, com abordagens sobre tecnologias e educação. Com relação às tecnologias, destaca-se nesse período de sua carreira a abordagem sobre a questão da complexidade do fenômeno dos colégios invisíveis como importante assunto de interesse sociológico, em que ele aponta que não há dúvidas que a evolução das tecnologias de comunicação irá fazer surgir um novo modo de colégio invisível, mas que é improvável uma substituição total dos canais de comunicação convencionais pelas redes eletrônicas e pelas telecomunicações. Cronin também menciona a incerteza em saber até que ponto a inovação tecnológica irá estimular a ampliação da base participativa e reduzir a distribuição desigual de benefícios, sendo esta uma característica da situação prevalecente da ciência na década de 80. Sobre educação, destaca-se sua preocupação com as tendências de educação a distância e aprendizagem aberta no contexto da Biblioteconomia. O mesmo afirma que o esquema ideal de ensino à distância deve se esforçar para oferecer aos estudantes máxima variedade possível em métodos de ensino, suporte tutorial e interação em grupo, bem como flexibilidade na definição e direção de seus percursos de estudo. Esse debate é muito 
pertinente aos dias atuais em que os cursos a distância em Biblioteconomia estão em implementação, contribuindo com a curva crescente do gráfico de expansão da educação superior no Brasil. Cronin (1984) ressalta que a evolução da tecnologia educacional na última década tornou este um objetivo progressivamente mais realizável por meio da televisão, computadores pessoais e outros dispositivos tecnológicos.

\subsection{PERÍOdo dE 1985-1989: ÊNFASE NA INDÚSTRIA DA INFORMAÇÃo}

Nesta fase, Blaise Cronin ainda discute nos seus artigos temas como Marketing e Bibliometria, porém em menor escala, pois a sua maior ênfase é na indústria da informação, sua estrutura e dinâmica, sendo discutidos os seguintes aspectos: a evolução da sociedade da informação, a economia da informação e seus efeitos, a fragmentação das políticas governamentais, a excelência, a inovação, a vantagem competitiva por meio das tecnologias da informação, e a importância da imagem e da publicidade tanto para a criação de uma forte cultura organizacional, como enquanto agente de mudança na indústria da informação.

O emprego no setor da economica da informação neste período é tido como de rápido crescimento, contrapondo-se a estagnação e ao declínio nas indústrias manufatureiras tradicionais. Cronin (1986, p. 121) diz que a sociedade da informação chegou à maioridade nos anos 80 , apresentado os impactos socioeconômicos trazidos pela tecnologia da informação. O autor cita nove processos decorrentes desse contexto, a saber: amplificação, globalização, aceleração, massificação, descentralização, mistificação, transformação, intensificação e comercialização. A gestão eficaz dos fluxos de informação, a criação de novas ideias e de conhecimento, o desenvolvimento de uma forte indústria da informação e o melhoramento da comercialização de sistemas de informação, serviços e produtos nos próximos anos serão os determinantes críticos do sucesso econômico.

Instituições como as bibliotecas públicas, na perspectiva de Cronin, estão mal equipadas para competir no mercado de informação de alta tecnologia e alto custo, não simplesmente porque não possuem reservas de dinheiro para lançar 
novos empreendimentos, mas também porque elas não são tradicionalmente produtoras ou geradoras de informação. Tradicionalmente são convencionalmente mediadoras da informação, mas com a introdução das tecnologias digitais de informação e comunicação na vida profissional e doméstica as bibliotecas tradicionais correm o risco de que os provedores de informação escolherem, em algumas circunstâncias, contornar essa comunidade intermediária e comercializar seus produtos diretamente ao usuário final/consumidor. Ele aponta que seria de elevado interesse da população, se as agências do setor público envolvidas no negócio de fornecimento de informações fizessem parceria com organizações comerciais, a fim de trazer novos serviços e produtos online para melhorar sua receita. Em uma sociedade da informação plenamente desenvolvida, Cronin alerta para a prudência e atenção que se deve ter em demarcar as linhas entre os setores público e privado, não para sufocar ou dominar o outro, mas para não piorar a qualidade e o alcance/acesso aos serviços disponíveis por partes menos favorecidas da sociedade, ressaltando a responsabilidade social da Ciência da Informação.

Para Cronin (1987, p. 24) excelentes corporações, geralmente, exibem uma atitude positiva em relação à inovação, mas isso não significa que uma empresa esteja buscando constantemente "o novo". A inovação pode ser aplicada a rotinas, processos, atividades e produtos existentes e mecanismos de prestação de serviços. Para além da importância da criatividade, do carisma e da qualidade, Rafferty, Cronin e Davenport (1988, p. 295) afirma que a publicidade é um agente de mudança na medida em que a publicidade tem o poder de modificar a opinião pública. Os anúncios de alta tecnologia ajudaram a promover o uso de sistemas e produtos informáticos eficientes e eficazes. No entanto, publicidade tende a não promover ideias e filosofias radicais ou revolucionárias. A publicidade reforça o status quo e além disso promete benefícios para o consumidor. Rafferty, Cronin e Davenport (1988, p. 187) destaca que o poder da tecnologia da informação para agregar valor às operações de uma empresa aumenta à medida que esta percorre os cinco estágios da cadeia de valor: logística de entrada, operações, logística de saída, marketing e vendas, e por fim, serviço. 
Abordando a questão da convergência entre bibliotecas universitárias e centros de computação, Cronin (1989, p. 13) aponta que maior cooperação, perda de autonomia, diluição de papéis, maior ênfase na qualidade de serviço e satisfação do cliente serão características desta nova ordem que está a se constituir, significando desconforto para alguns e estímulo profissional para outros. Segundo o autor, o gestor deste novo contexto deverá ser um gerente estrategista com visão e liderança política.

\subsection{ANOS 90: ÊNFASE NOS ESTUdos BibliométRICOS E NA CoMUNICAÇÃo Científica}

Os estudos bibliométricos de Blaise Cronin nos anos 90 versam inicialmente sobre a função social e cognitiva dos agradecimentos, além do significado destes em artigos científicos. Ele destaca que a citação é naturalmente um processo social, um mecanismo institucionalizado de reconhecimento dos pares. E discorre em vários artigos sobre a importância dos reconhecimentos e das citações, sobre o significado social e cognitivo destes no processo de comunicação científica, a questão do uso de citações na avaliação da produção científica de programas acadêmicos e de membros do corpo docente, e contempla também em suas abordagens as poucas regras formais que há em relação a isto na ciência.

Em uma de suas publicações, por exemplo, ele descreve o destino de 101 manuscritos rejeitados pelo Journal of Documentation durante os anos de 1981 a 1989. O objetivo do artigo foi verificar o quantitativo de publicações rejeitadas que são submetidas com sucesso em outro periódico, sob a hipótese central de que artigos rejeitados por um periódico, se publicados posteriormente, aparecem em um periódico de menor hierarquia ou prestígio. $\mathrm{O}$ aspecto mais difícil para tal estudo foi identificar uma amostra adequada de artigos rejeitados. $O$ acesso aos 101 artigos rejeitados, juntamente com 50\% dos comentários feitos pelos avaliadores, incluindo a carta de rejeição (parecer) do editor-chefe, foi possibilitado devido Blaise Cronin ter sido membro do conselho editorial do Journal of Documentation por vários anos. Esse acesso foi permitido sob a 
condição de que o anonimato dos autores rejeitados seria preservado. Esta pesquisa de Blaise Cronin foi desenvolvida em coautoria com Mckenzie, em 1992, e teve como principais limitações: problemas para acessar os números suficientes de artigos rejeitados; preservação de confidencialidade; confirmanção da semelhança entre rejeitados e publicados; adequação da cobertura oferecida por um determinado serviço secundário; dificuldade em determinar a razão real para a rejeição de um manuscrito, e validade do fator de impacto como calibrador de qualidade. No entanto, o método descrito por ele tem um potencial considerável, tanto como uma ferramenta de gestão editorial local, como também um mecanismo para uma melhor compreensão do tráfico de sistema de publicação num contexto competitivo.

Em 1992, Cronin comenta em um de seus artigos, as impressões que tivera sobre o estágio atual no ensino de estudos da informação/ciência internacionalmente, e cita o Brasil nesse rol de experiências. Ele menciona que essas impressões foram obtidas através de visitas in loco, seja para o propósito de ensinar, atuando como examinador externo, realizando pesquisas ou trabalhos de consultoria. Ele cita que em alguns casos, se envolveu ativamente como membro da equipe no projeto e em lançamento de um programa, como por exemplo, o Programa Regional da UNESCO em estudos de informação realizado na e pela Universidade de Simon Bolivar na Venezuela; o programa de Mestrado em estudos de informação em desenvolvimento na Universidade Nacional Autônoma de México; em outros, ele agiu como facilitador, como por exemplo, durante um ano de atuação em Programa de Especialização em

Gestão da Informação na Universidade Federal de Minas Gerais no Brasil; e em outros como uma caixa de ressonância, como por exemplo, repercutindo o Programa de Gestão a ser criado na Hungria pela OMIKK. No entanto, a experiência relevante mais próxima de sua realidade, segundo o próprio Blaise Cronin, consistiu no estabelecimento de um Mestrado em Gestão da Informação (1986) e de um Programa de Graduação em Ciência da Informação (1988) na Universidade de Strathclyde.

Cronin (1992, p. 198, grifo nosso) a respeito de sua experiência de ensino no Brasil nos anos 90, diz o seguinte a respeito da hermenêutica social: 
Dois anos atrás, durante uma sessão de planejamento curricular de gestão na Universidade Federal de Minas Gerais estava curioso para saber por que as propostas apresentadas incluíam uma aula sobre semiótica. Basicamente, a intenção era treinar os alunos na arte da interpretação: como pegar pistas, decodificar enunciados políticos e manifestos, identificar e dar sentido aos fracos sinais ambientais, e, literalmente, em muitos casos, como ler nas entrelinhas (a mídia no Brasil é altamente concentrada e a cobertura de notícias é facilmente manipulada). Essa experiência me convenceu de que qualquer programa de estudos de informação digno do nome deve incorporar um componente de hermenêutica social.

Além da ênfase supracitada, Cronin, já em meados dos anos 90, também abordou outras questões relevantes e emergentes para a época, tais como: hipertexto, internet e inteligência competitiva. Ele abordou a Internet como uma importante ferramenta em potencial para informação estratégica em empresas comerciais, em tempos que o compartilhamento de conhecimento se tornou um benefício importante para ingresso na comunidade em rede e global. Muitas empresas, grandes e pequenas, começaram a usar a Internet para ganhar vantagem em um ambiente de negócios cada vez mais competitivo. Cronin inferia nos anos 90 que a Internet seria a próxima grande fase na evolução da função de inteligência competitiva em organizações avançadas, especialmente à medida que a comercialização em rede se intensificaria. Ele discorreu sobre o uso comercial da Internet para fins de inteligência e sugeriu que existe um extenso, sofisticado e uso criativo da Internet em apoio à inteligência competitiva nas organizações. Há uma melhoria, neste contexto, no monitoramento do ambiente competitivo com maior facilidade do que antes, graças ao crescente e facilitado acesso à internet. De fato, essa realidade aconteceu e se intensificou, sobretudo neste início de século XXI.

Na segunda metade dos anos 90, Cronin aborda a Web e a Segurança da Informação, sem deixar de lado as questões bibliométricas que são sempre recorrentes em suas atividades de pesquisa. Ele se dedica a investigar o motivo dos estudiosos explorarem certos tipos de recursos de informação, enquanto escolhem ignorar ou abandonar outros; aborda o uso de citações como indicadores de produtividade acadêmica no contexto do sistema acadêmico de recompensa; a Web e seu efeito transformador sobre a maneira dos cientistas e 
estudiosos acessarem informações e apresentarem os resultados de suas pesquisas para comunidades de pares distribuídas globalmente; e apresenta, também, uma revisão sobre o desenvolvimento da educação à distância e a aprendizagem distribuída, especificamente, descrevendo a dinâmica estrutural do mercado virtual emergente para produtos e serviços de aprendizagem.Acerca deste último ponto de sua agenda de pesquisa, Cronin (1998) destaca que é evidente que o tamanho do mercado de educação a distância vai crescer de forma rápida e significativa no século XXI.

Por fim, quanto à abordagem sobre segurança da informação em 1999, Blaise Cronin menciona a guerra da informação no contexto militar e demais contextos sociais. Ele produziu uma pesquisa em que afirma que os efeitos sociais da computação seriam enriquecidos com a admissão do léxico "guerra de informação" e do "terrorismo informacional", e pela exploração sistemática das prováveis implicações em longo prazo e de suas tendências.

\subsection{ANOS 2000: ÊNFASE NA BibliometriA, NA EdUCAÇÃo e No SOCIAL}

Cronin começa os anos 2000 destacando que quanto mais um negócio depende de informações e sistemas sofisticados, maior a sua vulnerabilidade ao ataque furtivo. Discorre sobre guerra de informação e terrorismo líquido, uma discussão que decorre de um estudo dele iniciado no fim dos anos 90. Destaca que a guerra de informação irá exigir que as empresas e os governos implementem procedimentos de segurança de sistemas de informação e desenvolvimento de inteligência estratégia e capacidade de contrainteligência.

Apesar do exposto acima, esta não é a ênfase de suas publicações nos anos 2000. Trata-se apenas de um fechamento das discussões sobre o tema no século XX, pois o século XXI para Blaise Cronin, conforme fica evidenciado pelos seus artigos, é permeado por uma ênfase na educação e no social, mantendose os estudos bibliométricos, porém em coautoria, e não mais em autoria individual como se observava nas duas décadas anterioes.

Dentre as principais discussões realizadas por Cronin neste período, destacam-se: uma breve visão geral histórica dos estudos sobre publicação 
científica, enfocando o papel do autor e da confiança na comunicação científica e avalia até que ponto as tendências atuais da comunicação biomédica pode ser um prenúncio do desenvolvimento de outras disciplinas; a educação superior anglo-americana na perspectiva da gestão do conhecimento e da cultura organizacional; as tendências de agradecimentos na literatura de pesquisa em Ciência da Informação, em que o reconhecimento dos pares tornou-se um elemento institucionalizado do processo de comunicação científica, refletindo o crescimento cognitivo e complexidade estrutural da pesquisa contemporânea; o comércio eletrônico e as oportunidades para os produtores de produtos e serviços pornográficos; entre outros temas. Cronin (2002) afirma que os estudos de informação estão sendo descentralizados, incluindo temáticas como: interação humano-máquina, gestão do conhecimento, arquitetura da informação, informática social e economia da informação; alcançando, portanto, outros contextos.

O maior destaque no fim da primeira década do século XXI é um artigo de 2008, intitulado "A virada sociológica em Ciência da Informação", em que Blaise Cronin aborda a história social da $\mathrm{Cl}$. Ele traça a influência do pensamento social científico no desenvolvimento da base intelectual do campo, e discorre sobre os domínios dos estudos sociais de ciência, ciência e tecnologia, e sistemas sociotécnicos. Esta temática, pela sua relevância epistemológica, será abordada com maior aprofundamento na seção 4 deste presente artigo.

No período de 2010 a 2014, abrangendo o início da segunda década do século XXI, observa-se um foco dos estudos em bibliometria, sobretudo em coautoria. Curioso destacar que um dos pontos mais discutidos nesses estudos é a importância e o crescimento da autoria colaborativa, seguido da questão da revisão por pares.

A seguir, apresentamos um quadro que resume a trajetória históricoevolutiva do pensamento e das contribuições teórica de Blaise Cronin nesses 34 anos de carreira (1980-2014). 


\section{Quadro 1 - Síntese histórico-evolutiva da produção científica de Cronin na Cl}

\begin{tabular}{|c|c|c|}
\hline Período & Ênfase & Abordagem \\
\hline $\begin{array}{c}1980 \\
a \\
1984\end{array}$ & $\begin{array}{l}\text { Marketing e } \\
\text { Gestão da } \\
\text { Informação }\end{array}$ & $\begin{array}{l}\text { Abordagens centradas no marketing (necessidade e satisfação do } \\
\text { usuário em bibliotecas) e na gestão da informação (crescente } \\
\text { importância dos recursos de informação). Aborda os efeitos da } \\
\text { crise econômica nas bibliotecas, o novo papel do bibliotecário } \\
\text { frente às novas tecnologias, a complexidade dos colégios } \\
\text { invisíveis na comunicação científica e as tendências de educação } \\
\text { a distância em Biblioteconomia. }\end{array}$ \\
\hline $\begin{array}{l}1985 \\
a \\
1989\end{array}$ & $\begin{array}{l}\text { Indústria da } \\
\text { informação }\end{array}$ & $\begin{array}{l}\text { Aborda a evolução da sociedade da informação, a economia da } \\
\text { informação e seus efeitos, a fragmentação das políticas } \\
\text { governamentais, a excelência, a inovação, a vantagem } \\
\text { competitiva por meio das tecnologias da informação, e a } \\
\text { importância da imagem e da publicidade tanto para a criação de } \\
\text { uma forte cultura organizacional, como enquanto agente de } \\
\text { mudança na indústria da informação. }\end{array}$ \\
\hline $\begin{array}{l}\text { Anos } \\
1990\end{array}$ & $\begin{array}{c}\text { Estudos } \\
\text { bibliométricos } \\
e \\
\text { Comunicação } \\
\text { científica }\end{array}$ & $\begin{array}{l}\text { Aborda a função social e cognitiva dos agradecimentos em artigos } \\
\text { científicos; a citação como processo social e mecanismo de } \\
\text { reconhecimento entre os pares; a questão da rejeição de artigos } \\
\text { científicos e sua publicação em periódicos de menor hierarquia e } \\
\text { prestígio; experiências internacionais em estudos de informação; } \\
\text { e assuntos emergentes para a comunicação científica (hipertexto, } \\
\text { internet, inteligência competitiva, web e segurança da } \\
\text { informação). }\end{array}$ \\
\hline $\begin{array}{l}\text { Anos } \\
2000\end{array}$ & $\begin{array}{l}\text { Bibliometria, } \\
\text { Educação e } \\
\text { Sociedade }\end{array}$ & $\begin{array}{l}\text { Aborda uma breve visão geral histórica dos estudos sobre } \\
\text { publicação científica, com foco no papel do autor e a confiabilidade } \\
\text { na comunicação científica; a educação superior anglo-americana } \\
\text { na perspectiva da gestão do conhecimento e da cultura } \\
\text { organizacional; as tendências de agradecimentos na literatura de } \\
\text { pesquisa em Ciência da Informação; o comércio eletrônico e as } \\
\text { oportunidades para os produtores de produtos e serviços } \\
\text { pornográficos; a descentralização dos estudos de informação } \\
\text { (emergência de temas como: interação humano-máquina, gestão } \\
\text { do conhecimento, arquitetura da informação, informática social e } \\
\text { economia da informação); a história social da Cl; e o crescimento } \\
\text { e a importância da autoria colaborativa. }\end{array}$ \\
\hline
\end{tabular}

Fonte: Elaborado pelos autores (2018).

A análise da produção científica de Blaise Cronin possibilitou refletir também sobre a informação e a história social da $\mathrm{Cl}$ conforme veremos nas seções seguintes, a começar pelo uso da informação como recurso estratégico nas organizações.

\subsection{Blaise Cronin e a Informação Enquanto Recurso Estratégico ORgANIZACIONAL}

Embora o presente trabalho não contemple em sua abordagem os livros publicados por Blaise Cronin, a reflexão apresentada nesta seção toma por base 
livros e artigos encontrados na literatura científica brasileira do campo da Biblioteconomia e da Ciência da Informação que trazem menções a Cronin, quando discorrem sobre informação enquanto recurso estratégico organizacional.

Inicialmente é preciso destacar a indissociabilidade entre informação, estratégia de gestão e marketing no contexto organizacional. Talvez por isto Blaise Cronin tenha dedicado parte de sua carreira a estudar Marketing em Bibliotecas do ponto de vista de um cientista da informação. Além disto, sua preocupação nos estudos bibliométricos acerca da citação e do reconhecimento pelos pares, nos motivou a investigar a presença de Cronin nas publicações da pesquisadora de maior referência nos estudos brasileiros de Marketing em Unidades de Informação, a saber: a bibliotecária e professora Sueli Angélica do Amaral.

Discorrendo sobre a responsabilidade profissional dos bibliotecários que atuam em unidades de informação, Amaral (1998, p. 38) cita Blaise Cronin para evidenciar as habilidades requeridas para que estes profissionais enfrentem os desafios impostos neste contexto. Os desafios elencados por ela são: perceber a todo e qualquer tipo de unidade de informação como organização, com "negócios", respeitando-se suas peculiaridades; ampliação e melhoria da imagem organizacional destas unidades de informação; melhoria da atuação, orientada para atualização da oferta de produtos e serviços informacionais; educação continuada de toda a equipe da biblioteca, incluindo a do gerente; e a necessidade de se evidenciar o valor da cooperação nacional e internacional entre unidades de informação. Para tal, destaca que:

Entre as habilidades exigidas, principalmente para os que lidam com a informação automatizada, Blaise Cronin, em conferência proferida durante o Simpósio Internacional sobre a informação no terceiro milênio, em Belo Horizonte, em novembro de 1992, ressaltou a necessidade de desenvolver as habilidades interpessoais e de comunicação, acima das habilidades técnicas. Segundo Cronin, essas habilidades são consideradas importantes em função da relevância do saber como conhecer o comportamento dos usuários em relação à busca e uso da informação. Daí o conferencista destacar a ênfase que deve ser dada à administração dos recursos disponíveis. Além disso, afirma que as informações precisam ser confiáveis. Para ele valerá a qualificação e a competência individual de cada 


$$
\text { profissional (AMARAL, 1998, p. 38). }
$$

Não somente no contexto do marketing a informação se apresenta como recurso estratégico. O conceito de informação é percebido em várias publicações de Blaise Cronin. Ao longo de sua carreira, Cronin mencionou no início da década de 80 o conceito de informação útil, ao discorrer sobre o uso e necessidades de informação dos usuários pesquisadores da área de agricultura. Cronin (1980, p. 425) afirma que informação útil, neste contexto, é compreendida como sendo informação publicada em revistas, livros e relatórios, e julgados de boa qualidade para os fins organizacionais e de negócios daqueles que dela se servem. Ele menciona esse conceito discorrendo sobre informações científicas sobre agricultura produzidas por cientistas do mundo todo e reunidas em publicação impressa sob o formato de resumos informativos no âmbito dos Escritórios Agrícolas Commonwealth (Commonwealth Agricultural Bureaux CAB).

Blaise Cronin, ainda nos anos 80, diz que a informação se tornou a alma do século XX em termos de mercadoria (também se fala de informação como um anti-commodity), e que esta é vista como um facilitador de mudanças, um transformador de relações tradicionais, e como a base futura do poder financeiro, político e social. Ele afirma que em meados dos anos 80 alguns governos nacionais tomaram consciência da importância da informação como mercadoria comercializável e como base da prosperidade econômica.

Na segunda metade dos anos 90, Cronin afirma que no mundo da Web, os recursos cognitivos são extraordinários: uma miscelânea de objetos de informação digital (por exemplo, textos, imagens, dados, streaming de vídeo) podem ser empacotados e (re)configurados com uma facilidade que não pode ser igualada pelas ferramentas de produção do mundo da impressão. Ele aponta que precisamos desenvolver uma noção mais rica de como diferentes comunidades de prática recorrem a diferentes gêneros textuais e narrativos em seus trabalhos e a importância dos meta-comentários.

Nos anos 2000, Cronin evidencia que os estudos de informação se baseiam e contribuem em outros campos científicos. Menciona que o campo da Biblioteconomia e da Ciência da Informação se tornou um exportador de ideias 
de sucesso. Os estudos de informação começaram a contribuir significativamente para as literaturas de áreas como Ciência da Computação, Engenharia, Negócios e Gestão, em uma relação de interdisciplinaridade (CRONIN, 2008). Verifica-se, neste contexto, o uso da informação como recurso estratégico na ciência para produção de novos conhecimentos e geração de vantagem competitiva, para além dos ambientes empresarias ou das organizações públicas administrativas e governamentais. É possível encontrar uma rica discussão a respeito desse assunto no livro Elements of Information Management, publicado por ele em coautoria com Elisabeth Davenport em 1991. Interessante observar e destacar que Blaise Cronin possui dois artigos publicados no Brasil. Enquanto um deles aborda a educação em Biblioteconomia e Ciência da Informação, o outro aborda temática relevante para a presente discussão, o qual é intitulado "Esquemas conceituais e estratégias para a gerência da informação", publicado em 1990, na Revista da Escola de Biblioteconomia da UFMG, possivelmente oriundo da época em que o Cronin lecionou no curso de especialização oferecido nesta época. Para países em desenvolvimento como o Brasil, a principal mensagem do artigo é que enquanto a informação não for valorizada como um recurso para a tomada de decisão, o ciclo de inferioridade não será quebrado, pois não haverá vantagem competitiva. Para Cronin (1990, p. 218), é preciso investir na ideia que "a informação funciona como um ativo recurso econômico". As possibilidades, portanto, evidenciadas nos artigos de Blaise Cronin recuperados pelo Portal de Periódicos da CAPES são muitas e nos levam a refletir também sobre os aspectos sociais, econômicos e políticos da Ciência da Informação.

\section{CIÊNCIA DA INFORMAÇÃO NA PERSPECTIVA SOCIAL}

Talvez o artigo intitulado "A virada sociológica em Ciência da Informação", publicado em 2008, seja um dos que merece maior destaque dentre as mais recentes publicações de Blaise Cronin, contribuindo para que possamos ampliar nossa visão e compreensão acerca deste campo científico. Trata-se de um ponto de partida para uma reflexão que não se esgota na presente obra, mas que se 
inicia a partir do que já foi apresentado e discutido até então.

Cronin (2008) estudou por quase três décadas a literatura das ciências sociais e comportamentais, especificamente sobre sociologia da ciência e mais recentemente sobre informática social. Dois de seus livros são oriundos destes estudos. Para ele, os subcampos da Ciência da Informação, em especial os que ele trabalha (comunicação científica, análise de citações, cienciometria), conforme constatamos nesse artigo, evoluíram e amadureceram tomando por base as ideias teóricas e metodológicas das Ciências Sociais.

A Ciência da Informação é descrita por ele como um campo relativamente jovem e de modesto tamanho, e que tem interagido com outros campos para seu próprio enriquecimento intelectual e para sua maturidade teórica, e até mesmo metodológica. Isto não é visto de forma negativa ou problemática por ele, e o mesmo cita Gernot Wersig para dizer que o trabalho inter-conceitual é característico de qualquer nova ciência ou ciência pós-moderna.

Corroborando com Silva e Freire (2012), sabemos que Blaise Cronin (2008) compreende que os conceitos robustos que compõem o núcleo intelectual do campo (por exemplo, informação, conhecimento e representação de comunicação) não são de propriedade exclusiva da Ciência da Informação, nem susceptível de serem organizados em uma proposta consistente, sem considerar a adição criteriosa de perspectivas e abordagens adotadas por outras áreas, como a Ciência da Computação, Lingüística, Filosofia, Psicologia e Sociologia, bem como dos campos mais recentes, como a ciência cognitiva e a interação homem-máquina. Podemos afirmar que, até mesmo o próprio conceito e a configuração identitária da Ciência da Informação, são difíceis de estabelecer com uniformidade dentro do campo. A própria natureza do objeto de pesquisa, a informação, exige que as perspectivas sejam plurais, implicando em abordagens inter e multidisciplinares.

Blaise Cronin não é o único ou primeiro a perceber a relevância social deste campo científico. No entanto, para fins dessa reflexão, nos interessa o que ele nos apresenta a partir de sua perspectiva e seu artigo. A Ciência da Informação possui significativamente um caráter social, e também uma forte tradição nas humanidades. Uma reflexão interessante evidenciada pelo autor 
consiste em pensarmos até que ponto o aspecto social se sobrepõe ao cognitivo no contexto, por exemplo, da comunicação científica. Cronin (2008) diz que o fato de considerar que preexistem laços sociais entre autores podem moldar as práticas de citação. E isto deu origem ao que podemos chamar de "mapeamento sócio-bibliométrico" e "sócio-cienciométrico". Um ponto que tem recebido pouca atenção nos estudos bibliométricos, conforme alertado por Cronin, é que os colégios invisíveis possuem tanto uma estrutura cognitiva, quanto uma estrutura social. Ele verifica, portanto, um potencial para cooperação entre a bibliometria e a análise de redes sociais.

Uma crítica que Cronin (2008) apresenta é acerca do construtivismo social que nos campos da Sociologia da Ciência é muito popular desde os anos 80 , e que muitos intelectuais desse domínio (por exemplo Bijker, Bloor, Collins, KnorrCetina, Latour, Mackenzie, Pinch, Woolgar) são citados rotineiramente nas principais revistas de Ciência da Informação; mas infelizmente, há pouca citação no sentido inverso: a Ciência da Informação ouve, mas não é ouvida, ou então é amplamente ignorada pelas Ciências Sociais.

Sociólogos, tanto clássicos e contemporâneos, conforme afirma Cronin (2008) e suas teorias sociológicas, têm sido importados para a Ciência da Informação. Entre os nomes mais citados e suas respectivas abordagens estão Pierre Bourdieu $(1983,1999,2004,2009,2011)$ acerca do capital social e cultural, Manuel Castells (1999) sobre a sociedade em rede, Harold Garfinkel (1967) que propôs a etnometodologia, Anthony Giddens $(1991,2002)$ sobre estrutura social e as consequências da modernidade, Bruno Latour (2012) com a teoria ator-rede e Robert Merton $(1970,1973)$ acerca da sociologia da ciência.

Cronin (2008) afirma que embora a Ciência da Informação tenha sido receptiva ao pensamento sociológico, é provavelmente errôneo falar de uma "virada sociológica" como tal foi proposto no título do artigo de 2008. O mesmo reconhece que não está claro que houve de fato um momento histórico particular em que o campo se tornou de algum modo sociologicamente iluminado, ou mudou paradigmaticamente como resultado da exposição concentrada em insights de sociologia. Por fim, Cronin (2008) não nos deixa esquecer que a perspectiva social da Ciência da Informação possui raízes claras e bem definidas 
na Biblioteconomia e na Documentação.

\section{POSSIBILIDADES DE NOVOS ESTUDOS E PESQUISAS NA CI BRASILEIRA}

A análise da produção científica de Blaise Cronin oportunizou identificar temáticas que poderão ser estudadas em maior nível de aprofundamento pelos cientistas da informação, sobretudo os que estão em formação nos Programas de Pós-Graduação em Ciência da Informação no Brasil.

A partir deste estudo foi possível estabelecer conexões temáticas para o desenvolvimento de novos estudos, considerando a viabilidade científica e a relevância social. O quadro 2 expressa a proposta de novos estudos e pesquisas que poderão ser executados no campo da Ciência da Informação brasileira. Foi construído com base na Síntese histórico-evolutiva da produção científica de Blaise Cronin na $\mathrm{Cl}$, apresentada anteriormente.

As possibilidades não se esgotam na proposta que apresentamos neste trabalho. Assim como propomos temáticas que merecem atenção por parte dos nossos cientistas da informação, nos comprometemos em continuar investigando a produção científica de Blaise Cronin, e as próximas pesquisas deverão analisar os livros, os editoriais, as resenhas e os resumos expandidos de comunicação que são tão importantes quanto os artigos científicos analisados no presente estudo.

Quadro 2 - Proposta de estudos e pesquisas para a Ciência da Informação

\begin{tabular}{|c|c|}
\hline Ênfase & Temáticas Sugeridas \\
\hline $\begin{array}{c}\text { Marketing e } \\
\text { Gestão da Informação }\end{array}$ & $\begin{array}{l}\text { - Marketing, Gestão, Tecnologia e Dados Abertos em unidades de } \\
\text { informação; } \\
\text { - Políticas de informação para gestão de recursos informacionais e para } \\
\text { o desenvolvimento de competências digitais; } \\
\text { - Estratégias de marketing digital para bibliotecas públicas e multiníveis. }\end{array}$ \\
\hline $\begin{array}{c}\text { Economia e Indústria da } \\
\text { informação }\end{array}$ & $\begin{array}{l}\text { - Governança multinível no contexto das bibliotecas públicas; } \\
\text { - Participação do bibliotecário na economia da informação no Brasil; } \\
\text { - Políticas governamentais para o setor de informação no Brasil; } \\
\text { - Publicidade em unidades de informação nos setores público e privado; } \\
\text { - Informação e comércio eletrônico no Brasil. }\end{array}$ \\
\hline $\begin{array}{l}\text { Estudos bibliométricos } \\
\text { e Comunicação } \\
\text { científica }\end{array}$ & $\begin{array}{l}\text { - Uso inteligente da internet por profissionais da informação; } \\
\text { - Segurança da informação em unidades de informaçãa; } \\
\text { - Estudos sociais de informação em programas de pós-graduação } \\
\text { brasileiros; }\end{array}$ \\
\hline
\end{tabular}




\begin{tabular}{|l|l|}
\hline & - Ciência Aberta e os sistemas de publicação eletrônica dos periódicos \\
& científicos brasileiros: revisão por pares, rejeição de artigos, citação e \\
agradecimentos; & - Métodos de pesquisa em Ciência da Informação; \\
& - Atuação do profissional da informação com inteligência competitiva e \\
produção científica nas organizaçães que investem em Pesquisa e \\
Desenvolvimento (P\&D).
\end{tabular}

Fonte: Elaborado pelos autores (2019).

\section{CONSIDERAÇÕES FINAIS}

Grande parte da pesquisa de Blaise Cronin concentra-se na colaboração em ciência, comunicação acadêmica, análise de citações, sistema de recompensa acadêmica e cibermétricas, além da interseção da Ciência da Informação com os estudos sociais da ciência. Ele também publicou extensivamente sobre tópicos como guerra de informação, marketing, gerenciamento de informação e conhecimento, análise competitiva e inteligência estratégica.

Como bibliométrico, Blaise Cronin não abandona a bibliometria em nenhum momento de sua carreira e aponta que as técnicas bibliométricas podem ser usadas não somente para expor as estrutura de um campo, descrevendo padrões de publicação, coautoria, citação e reconhecimento, mas também para evidenciar questões sociais e amplas, a exemplo do estudo de gênero que destaca a participação das mulheres na ciência.

A análise de 34 anos de carreira de Cronin é de suma importância, pela oportunidade de apresentar a trajetória intelectual de importante cientista da informação, revelando a sua rede conceitual que mostra um pesquisador capaz de antever as temáticas e problemas de informação da sociedade contemporânea.

Contudo, é preciso considerar outros tipos de publicações que não foram contemplados no apresente estudo, a saber: resenhas, editoriais, resumos expandidos de comunicação e livros; e continuar a investigar as suas 
contribuições teóricas para este campo científico. Certamente, teremos novos insights e novas descobertas que serão úteis para o contínuo desenvolvimento e fortalecimento do corpo teórico da Ciência da Informação no Brasil.

Após um período de doze meses estudando oitenta e um artigos científicos de Blaise Cronin, concluímos o estudo cientes da contribuição responsável que ele traz para o Brasil ao evidenciar que o pensamento de Cronin apresenta-se contemporâneo, relevante e necessário tanto para o campo científico, quanto para a atuação profissional dos bibliotecários. Assim como um farol é um guia de sinalização naútica para os navegadores e suas embarcações em alto mar alcançarem a terra firme, este artigo, por meio da revisão da produção científica de Cronin, se propõe a ser uma bússula, colaborando e inspirando novos e profícuos estudos sociais em Ciência da Informação.

\section{REFERÊNCIAS}

AMARAL, S. A. do. Marketing: abordagem em unidades de informação. Brasília: Thesaurus, 1998.

BARDIN, Laurence. Análise de conteúdo. Lisboa: Edições 70, 1977.

BEBBINGTON, L.; CRONIN, B. Courtship and Competition on Campus: the convergence of university libraries and computing centres. Library Review, v. 38, n. 2, p. 7-17, 1989. Disponível em: https://doi.org/10.1108/00242539410134147. Acesso em: 02 ago. 2018.

BOURDIEU, P. Questões de sociologia. Rio de Janeiro: Marco Zero, 1983.

BOURDIEU, P. A reprodução. 2. ed. Petrópolis: Vozes, 2009.

BOURDIEU, P. O senso prático. Petrópolis: Vozes, 2011.

BOURDIEU, P. (Org.). A miséria do mundo. 3. ed. Petrópolis: Vozes, 1999.

BOURDIEU, P. [Coletânea de textos]. In: NOGUEIRA, Maria Alice; CATANI, Afrânio (Org.). Escritos de Educação. 6. ed. Petrópolis: Vozes, 2004.

CASTELLS, M. A sociedade em rede. 8. ed. atualizada. São Paulo: Paz e Terra, 1999. 1v.

CRONIN, B. Esquemas conceituais e estratégicos para a gerência da informação. R. Esc. Biblioteconomia UFMG, Belo Horizonte, v. 19, n. 2, p. 
195-220, set. 1990. Disponível em:

http://www.brapci.inf.br/index.php/res/v/70793. Acesso em: 02 ago. 2018.

CRONIN, B. From paradigm to practice: the logic of promotion, Aslib

Proceedings, v. 33, n. 10, p. 383-392, 1981. Disponível em:

https://doi.org/10.1108/eb050814. Acesso em: 02 ago. 2018.

CRONIN, B. Holding the center while prospecting at the periphery: domain identity and coherence in North American information studies education, Education for information, v. 20, n. 1, p. 3-10, 2002. Disponível em: https://content.iospress.com/journals/education-for-information/20/1. Acesso em: 02 ago. 2018.

CRONIN, B. Information science in the international arena: an educator's perspective, Aslib Proceedings, v. 44, n. 4, p. 195-202, 1992. Disponível em: https://doi.org/10.1108/eb051271. Acesso em: 02 ago. 2018.

CRONIN, B. New technology and marketing-the challenge for librarians, Aslib Proceedings, v. 34, n. 9, p. 377-393, 1982a. Disponível em: https://doi.org/10.1108/eb050853. Acesso em: 02 ago. 2018.

CRONIN, B. Taking the measure of service, Aslib Proceedings, v. 34, n. 6, p. 273-294, 1982b. Disponível em: https://doi.org/10.1108/eb050848. Acesso em: 02 ago. 2018.

CRONIN, B. The marketing of Public Library Services in the United Kingdom: he Rationale for a Marketing Approach, European Journal of Marketing, v. 18, n. 2, p. 33-44, 1984. Disponível em:

https://doi.org/10.1108/EUM0000000004767. Acesso em: 02 ago. 2018.

CRONIN, B. CAB abstracts: a global view. Aslib Proceedings, v. 32, n. 11, p. 425-437, 1980. Disponível em: https://doi.org/10.1108/eb050763. Acesso em: 02 ago. 2018.

CRONIN, B. The information society. Aslib Proceedings, v. 38, n. 4, p. 121129, 1986. Disponível em: https://doi.org/10.1108/eb051006. Acesso em: 02 ago. 2018.

CRONIN, B. Excellence under the microscope. Aslib Proceedings, v. 39, n. 1, p. 17-31, 1987. Disponível em: https://doi.org/10.1108/eb051036. Acesso em: 02 ago. 2018.

CRONIN, B. The eletronic academy revisited. Aslib Proceedings, v. 50, n. 9 , p. 241-254, 1998. Disponível em: https://doi.org/10.1108/eb051502. Acesso em: 02 ago. 2018.

CRONIN, B. The sociological turn in information science. Journal of Information Science, v. 34, n. 4, p. 465-475, 2008. Disponível em: 
https://journals.sagepub.com/doi/abs/10.1177/0165551508088944. Acesso em: 02 ago. 2018.

CRONIN, B.; CRAWFORD, R. Information Warfare: its application in military and civilian contexts. The Information Society, v. 15, p. 257-263, 1999.

Disponível em:

https://www.tandfonline.com/doi/abs/10.1080/019722499128420. Acesso em: 02 ago. 2018.

CRONIN, B.; MCKENZIE, G. The trajectory of rejection. Journal of Documentation, v. 48, n. 3, p. 310-317, 1992. Disponível em: https://doi.org/10.1108/eb026900. Acesso em: 02 ago. 2018.

DAVENPORT, L.; CRONIN, B. Vertical integration: corporate strategy in the information industry, Online Review, v. 10, n. 4, p. 237-247, 1986. Disponível em: https://doi.org/10.1108/eb024219. Acesso em: 02 ago. 2018.

ELO, S.; KYNGAS, H. The Qualitative Content Analysis Process. The Qualitative Content Analysis Process. Journal of Advanced Nursing, v. 62, n. 1, p. 107-115, abril 2008. Disponível em: https://doi.org/10.1108/eb051114. Acesso em: 02 ago. 2018.

GARFINKEL, Harold. Studies in ethnomethodology. New Jersey: Prentice Hall, 1967.

GIDDENS, A. As consequências da modernidade. São Paulo: Edusp, 1991. GIDDENS, Anthony. Modernidade e identidade. Rio de Janeiro: Zahar, 2002.

LATOUR, B. Reagregando o social: uma introdução à teoria do Ator-Rede. Salvador-Bauru: EDUFBA/EDUSC, 2012.

MERTON, R. K. The Sociology of Science. University of Chicago Press, 1973. MERTON, R. K. Sociologia, Teoria e Estrutura. São Paulo, Mestre Jou, 1970.

RAFFERTY, P.; CRONIN, B.; DAVENPORT,L. The rhetoric of promise: advertising in the information industry. Aslib Proceedings, v. 40, n. 11/12, p. 295-301, 1988. Disponível em: https://doi.org/10.1108/eb051036. Acesso em: 02 ago. 2018.

RICHARDSON, R. J. Pesquisa social: métodos e técnicas. 4. ed. São Paulo: Atlas, 2017.

SILVA, J. L. C.; FREIRE, G. H. de A. Um olhar sobre a origem da Ciência da Informação: indícios embrionários para sua caracterização identitária.

Encontros Bibli, v. 17, n. 33, p. 1-29, jan./abr., 2012. 
VERGARA, S. C. Métodos de pesquisa em administração. 4. ed. São Paulo: Atlas, 2010.

\title{
BLAISE CRONIN AND INFORMATION SCIENCE IN SOCIAL PERSPECTIVE
}

\begin{abstract}
Introduction: Discusses the social side of Information Science, ignoring a reflection on a social influence that is taking place in this field, a perception of Blaise Cronin's perception of information as a creative organizational resource, and the identification of the themes addressed by the researcher throughout career, or allowing us to know the influence of these theoretical assumptions in the scientific field. Objective: The objective of the article is to present to the Brazilian scientific community a reflection on the historical-evolutionary trajectory of the thought and the theoretical contributions of scientist Blaise Cronin and to Information Science. Methodology: Blaise Cronin retrieved by the CAPES Journal Portal used the techniques of bibliographic research and content analysis to study articles. Results: The study presented by Blaise Cronin over 34 years of career, conducts investigations with emphasis on marketing and management, information industry, bibliometrics and scientific communication. Evidence or potential contribution of this scientist to contemporary studies on Politics and Economy of Information, alterations of new research, from his scientific legacy. Conclusions: After a period of twelve months, studying eighty-one scientific articles by Blaise Cronin, concluding or studying studies on the responsibility responsible for him brings to the scientific field in Brazil and to show what Professor Cronin's thinking is contemporary, relevant and certainly for the scientific field, as well as the professional performance of librarians.
\end{abstract}

Descriptors: Information Science. Social Science. Epistemology of Information Science. Information Economy. Blaise Cronin.

\section{BLAISE CRONIN Y LA CIENCIA DE LA INFORMACIÓN EM PERSPECTIVA SOCIAL}

\begin{abstract}
RESUMEN
Introducción: Discute el lado social de la Ciencia de la Información, ignorando una reflexión sobre una influencia social que está teniendo lugar en este campo, una percepción de la percepción de la información de Blaise Cronin como un recurso creativo de organización, y la identificación de los temas abordados por el investigador a lo largo de carrera, o permitiéndonos conocer la influencia de estos supuestos teóricos en el campo científico. Objetivo: El objetivo del artículo es presentar a la comunidad científica brasileña una reflexión sobre la trayectoria histórico-evolutiva del pensamiento y las contribuciones teóricas del científico Blaise Cronin y la Ciencia de la Información. Metodología: las técnicas de investigación bibliográfica y análisis de contenido se utilizaron para estudiar los artículos de Blaise Cronin recuperados por el portal de la revista CAPES. Resultados: El estudio presentado por Blaise Cronin durante más de 34 años de carrera, lleva a cabo investigaciones con énfasis en marketing y gestión,
\end{abstract}


industria de la información, bibliometría y comunicación científica. Evidencia o contribución potencial de este científico a los estudios contemporáneos sobre Política y Economía de la Información, alteraciones de nuevas investigaciones, a partir de su legado científico. Conclusiones: Después de un período de doce meses, estudiar ochenta y un artículos científicos de Blaise Cronin, concluir o estudiar estudios sobre la responsabilidad responsable de él trae al campo científico en Brasil y mostrar lo que el pensamiento del profesor Cronin es contemporáneo, relevante y ciertamente para $\mathrm{El}$ campo científico, así como el desempeño profesional de los bibliotecarios.

Descriptores: Ciencias de la Información. Ciencias Sociales. Epistemología de la ciencia de la información. Economía de la información. Blaise Cronin. 